vice which draws patients from a large part of south $\mathrm{Ba}$ hia and northern Minas Gerais, and which is now in its $32^{\text {nd }}$ year of existence. Despite the problem I manage to keep up with my neurological work during about fifty hours each week.

To recapitulate, the authors of this excellent article are probably right in their thesis that Dom Pedro II suffered from sleep apnea, but in the absence of eye witnesses of his sleeping time and patterns, there is the less likely possibility that he suffered from the problem discussed in this letter.

\section{REFERENCES}

1. Doghrami K, Strohl KP. Sleep, sleep apnea. In The Merck Manual of Diagnosis and Therapy. Rahway NJ: 2006:499-502, 1834-1843.

2. Chapman AH, Almeida SV, Reis MA. EEG: leitura e interpretação. Petrópolis: EPUB, 2006:75.

3. Becker B. Distúrbios do sono. Rio de Janeiro Editora, 1993.

Vitória da Conquista

\title{
ABSENCE OF MRI EXAMS IN EPIDEMIOLOGICAL STUDIES CAN LEADS TO CLINICAL OVERDIAGNOSIS OF ALZHEIMER'S DISEASE AND UNDERDIAGNOSIS OF VASCULAR DEMENTIA
}

\section{TO THE EDITOR}

We would like to comment some methodological issues that arised from the interesting paper of Tascone et al. ${ }^{1}$ and that did not were cleared in the discussion. Until and unless we have neuropathological confirmation of diagnostic accuracy, our conclusions must be seriously questioned since we all know that the definitive diagnoses of Alzheimer's disease (AD), vascular dementia (VaD), and other dementias are based on neuropathological criteria. Obviously, this limitation should not hinder epidemiological studies like the excellent work of Tascone et al. However, caution should be taken related to the prevalence rates of each dementia form, since some of them are almost exclusively diagnosed with expensive neuroimaging methods as is the case of MRI for the correct diagnosis of an important and frequent form of dementia: Binswanger disease or subcortical vascular dementia. ${ }^{2}$ As the authors did not mentioned if they used CT or MRI scans in their patients and because MRI is an expensive method, we assume that most of their patients probably was examined with CT scans.

The predominance of $A D$ diagnosis found by the authors is remarkable (62.8\%), but is in consonance with international literature. These findings, however, may reflect an overdiagnosis of Alzheimer's disease to the detriment of vascular dementia, since individuals with silent cerebrovascular disease or even subcortical cerebrovascular disease may not be detected without using MRI scans. In fact, in their study the diagnosis of "other dementias" which comprises patients with vascular dementia (VaD) and other forms of dementia is surprisingly low (14.2\%), contradicting vascular dementia rates in other studies. ${ }^{3}$ Adding contribution to this debate, we should mention that one of the most important authorities in the field postulated that the two main causes of $\mathrm{VaD}$ - stroke and ischemic heart disease (IHD) - may be responsible for the majority of cases of dementia in the elderly. This author remembered that cerebrovascular disease (CVD) is the second leading cause of death worldwide. About $1 / 3$ of stroke survivors [range: $25-41 \%$ ] 65 years old and above develop $\mathrm{VaD}$ within 3 months following the ictus. In the USA alone, 125,000 new cases/year of $\mathrm{VaD}$ occur after ischemic stroke (about $1 / 3$ of the 360,000 incident cases of $A D)$. Therefore, more than 1 million elderly people are currently affected by poststroke VaD in the USA. Besides that, IHD leading to congestive heart failure (CHF) will become the leading cause of disability worldwide. Vascular cognitive impairment occurs in $26 \%$ of patients discharged from hospitals after treatment for CHF. Cognitive dysfunction correlates with left ventricular dysfunction and systolic blood pressure below $130 \mathrm{~mm} \mathrm{Hg}$. CHF is a leading cause of hospital admissions in Western nations ( 4.5 million cases in the USA alone) and is a growing problem in developing countries. Furthermore, over 800,000 patients/year undergo coronary artery bypass graft (CABG) surgery worldwide, including 300,000 patients in the USA. Measurable cognitive dysfunction occurs post-CABG in $80-90 \%$ of patients at hospital discharge. Long-term ( 5 years) incidence of cognitive defects is $42 \% 4,5$.

Other factor that may have contributed to the low incidence of $\mathrm{VaD}$ in this study should be the psychiatric ori- 
entation of their service. VaD patients, mainly those resulted from multi-infarct brain lesions, tend to seek for attention in neurological services.

\section{REFERENCES}

1. Tascone LS, Marques RCG, Pereira EC, Bottino C. Characteristics of patients assisted at an ambulatory of dementia from a university hospital. Arq Neuropsiquiatr 2008;66:631-635.

2. Korczyn AD. The underdiagnosis of the vascular contribution to dementia. J Neurol Sci 2005;15:229-230:3-6.

3. Korczyn AD. Mixed dementia--the most common cause of dementia. Ann N Y Acad Sci 2002;977:129-34.
4. Román GC. Vascular dementia may be the most common form of dementia in the elderly. J Neurol Sci 2002;15:7-10.

5. de la Torre JC. Alzheimer's disease prevalence can be lowered with non-invasive testing. J Alzheimers Dis 2008;14:353-359.

\author{
Leonardo Caixeta \\ Vânia Lúcia Soares \\ Cândida Dias Soares \\ Cognitive and Behavioral Neurology Unit \\ Hospital das Clínicas / Federal University of Goiás
}

\section{PROFESSOR CHARLES DAVID MARSDEN}

\section{TO THE EDITOR}

On September $29^{\text {th }}, 1998$, Professor C.D. Marsden died unexpected and prematurely at the age 60 years. ${ }^{1-3}$ Professor Marsden was considered at the time, one of the most important and productive clinical neuroscientists and his scientific contributions in the field of movement disorders were outstanding landmarks. He was one of the 10 most cited biomedical scientists worldwide with 1070 publications with emphasis on the physiology of movement, dystonia, myoclonus, tremor and Parkinson's disease, including the first descriptions of new movement disorders such as painful legs/moving toes syndromes, abdominal dyskinesias, reticular reflex myoclonus, cortical myoclonus, propriospinal myoclonus, gait ignition failure and primary writing tremor. ${ }^{1-4}$ Among his several classic papers was the one entitled "Mysterious motor function of the basal ganglia: the Robert Wartemberg Lecture", a cornerstone at the time, remaining to this day as one of the most cited papers in the field. ${ }^{5}$ Professor Marsden was the founder, along with Professor S. Fahn, of the Movement Disorders Society, as well as the editor of the Movement Disorders Journal and the Journal of Neurology, Neurosurgery and Psychiatry. ${ }^{1-3}$

During the last few years, the field of movement disorders has advanced tremendously, particularly due to the recent enlightenment coming from neurogenetics, molecular biology, neuro-imaging and also neurophysiology; the contributions of Professor Marsden, however, remain alive and au courant. During the latest edition of the International Congress of the Movement Disorders Society, in June 2008 in Chicago, several eminent authorities in this area recalled and recognized the diverse contributions left by the great master from Queen Square.
Ten years after his passing, it is fundamental to remember the seminal contributions of this outstanding neuroscientist, an icon of the $20^{\text {th }}$ century in the field of neuroscience.

Paraphrasing the disciples of Charcot, E. Brissau and Pierre Marie, in the article published in 1893 in the Revue Neurologique, entitled "Nécrologie de J-Martin Charcot", we can say that "recognition is the sweetest sensation" 6.

\section{REFERENCES}

1. Fahn S. Professor C.David Marsden. Arch Neurol 1999;56:119-120.

2. Lang AE. Professor Charles David Marsden. Neurology 1999; 52:14-15.

3. Lees AJ. C. David Marsden (April 15, 1938-September 29, 1998). Mov Disord 1999;14:3-5.

4. Marsden CD. The mysterious motor function of the basal ganglia: the Robert Wartemberg Lecture. Neurology 1982;32: 514-539.

5. Teive HA, Zavala JA, Iwamoto FM, Sá D, Carraro H Jr, Werneck LC. Contributions of Charcot and Marsden to the development of movement disorders in the $19^{\text {th }}$ and $20^{\text {th }}$ centuries. Arq Neuropsiquiatr 2001;59:633-636.

6. Brissaud E, Marie P. Nécrologie. J-M Charcot. Rev Neurol 1893; 16:29-30.

Hélio A.G. Teive

Renato Puppi Munhoz

Movement Disorders Unit / Neurology Service

Internal Medicine Department

Hospital de Clínicas / Federal University of Paraná

e-mail:hagteive@mps.com.br 